\title{
Evaluation of Reverse Logistics in Challenges within the Manufacturing Pharmaceutical Companies
}

\author{
Mpho Sharon Makgedi Makaleng ${ }^{1}$, Keith Richard Lambert ${ }^{2 *}$ \\ ${ }^{1}$ Lecturer in Supply Chain at the Tshwane University of Technology, Staatsartillerie Road, Pretoria, 0001, South Africa \\ ${ }^{2}$ Senior Lecturer in Supply Chain and Operations Management at Cardiff Metropolitan University, Llandaff Campus, Western Avenue, \\ Cardiff, CF5 2YB, United Kingdom
}

\begin{abstract}
The link between reverse logistics and logistics is being increasingly noted by logistics experts and researchers globally, especially in manufacturing pharmaceutical companies. This has led to the examination of reverse logistics challenges in manufacturing pharmaceutical companies. The main objective was to examine reverse logistics challenges in manufacturing pharmaceutical companies in the City of Tshwane (South Africa). The study aimed to find approaches to deal with the challenges of reverse logistics such as gatekeeping, managerial implications, technology, waste elimination, transportation, and product recalls within the industry. The study was empirical, and a quantitative approach was used. Furthermore, data analysis was conducted by using the Stata V13 statistical software where a descriptive analysis was employed. Questionnaires were posted via SurveyMonkey to the staff at fifty pharmaceutical companies. This resulted in a total of 127 respondents, which provided a response rate of $51 \%$. The findings indicated that manufacturing pharmaceutical companies face a variety of challenges; such as lack of skills and skills transfer, transport, and gatekeeping (amongst others), when dealing with reverse logistics. It is thus recommended that processes and strategies involved in reverse logistics should be known and taken into consideration because of the importance of reverse logistics in manufacturing pharmaceutical companies.
\end{abstract}

\section{Keywords:}

Reverse Logistics;

Manufacturing Pharmaceutical Companies;

City of Tshwane;

Reverse Logistics Challenges;

South Africa.

\section{Article History:}

Received: $\quad 02$ February 2021

Revised: 29 May 2021

Accepted: 27 June 2021

Published: 01 August 2021

\section{1- Introduction}

Reverse logistics happens daily for different firms in different industries and for different reasons. However, reverse logistics awards an opportunity for firms to differentiate and distinguish themselves, and to positively influence customer satisfaction, which helps in building consumer confidence in the company brand [1]. Reverse logistics includes several practices; ranging from re-use/re-sell, recycling, landfilling/suitable disposal, remanufacturing, incineration, repackaging, and, product returns management amongst others. There are several returns of medication that have occurred for different reasons in South Africa as well as globally. Venkatesh et al. (2017) mention that one of the very significant commercial sectors for the economy of any country is the pharmaceutical industry [2]. Researcher such as Ayvaz et al. [3], Trochu et al. [4], and John et al. [5] have all noted how reverse logistics has been receiving a lot of attention recently and these researcher have been doing research on this topic. Amongst the many reasons why this topic has been receiving a lot of attention lately is because firms had to develop their current strategies to be more sustainable due to factors such as the firm's green image, its political, social responsibility, and the economy [3]. In this study, the researcher has noted that

\section{* CONTACT: makalengMSM@tut.ac.za}

DOI: http://dx.doi.org/10.28991/esj-2021-01291

(C) 2021 by the authors. Licensee ESJ, Italy. This is an open access article under the terms and conditions of the Creative Commons Attribution (CC-BY) license (https://creativecommons.org/licenses/by/4.0/). 
reverse logistics development for staff members is a challenge and therefore management must consider this and implement training for staff and employ qualified personnel who are more confident in handling reverse logistics problems and challenges. Pienaar et al. (2012) define reverse logistics as "that part of returns management that plans, implements and controls the efficient, effective flow of goods and related information between the point of consumption and the point of origin to recapture value or properly dispose of the goods". Reverse logistics has been in existence as far back as forward logistics. The word logistics originates from the Greek adjective, logistikos, meaning 'skilled in calculating', and this relates to calculating or 'concerned' with reason [6]. The reverse logistics of medicine is different from the forward logistics. Forward logistics is when goods are moved from the supplier to the customer; reverse logistics is when goods are moved from the customer back to the supplier.

According to De Villiers et al. (2017), different family logistics terms can be split according to the number of areas of activities, and these include: Reverse Logistics, Military logistics, Business Logistics, Production Logistics, and Engineering Logistics [7]. Product returns occur worldwide and these cost a lot of money and an example of this is the Ford Kuga. The Ford Kuga 1.6-litre Ecoboost models that were produced from 2012 to 2014 were recalled in January (2017) due to several reports of the utility vehicles bursting into flames [8]. Another example in 2017, there was an outbreak of listeriosis, which was announced in March 2018 by the South African Minister of Health [9]. The source of the outbreak was at an Enterprise factory that produces polony and Vienna sausages, which is part of the Enterprise Group. These products were recalled as they threatened the lives of many individuals in different parts of the world (South Africa, Austria, Denmark, Finland, Sweden, and the UK) since the products were exported to other countries. The recall amounted to R415 million in losses. According to the Department of Health [10], there was a total of 1038 cases of listeriosis recorded by May of 2018, with a reported death rate of 208.

Products such as medicine cannot be recycled, refurbished, or resold and can only be disposed of, making it very costly when they are returned. However, Sorkun and Onay (2018) mention that managing reverse product flows effectively provides many benefits to firms [11]. When looking at this topic in South Africa, it was found that there is a lack of research within this field thus identifying a gap that needs to be investigated.

\section{1-1- Reverse Logistics in the Manufacturing Pharmaceutical Industry}

Reverse logistics includes handling goods returned due to damage, seasonal inventory, restock, salvage, recalls, excess inventory, recycling programs, hazardous material programs, obsolete equipment temperament, and asset recovery [12]. "Drug recalls are common for countries with well-defined regulatory guidelines that often involve defective products that pose health risks to patients" [2]. Recalls can be done if the drugs are a health hazard, mislabeled, or poorly packaged, have manufacturing defects, and are counterfeits (amongst others). This view is supported by Abbas (2018) [13] who writes that products may be returned by customers because they are dissatisfied with the product or the product has defects, etc.

The fundamental difficulties of reverse logistics processes, such as imprecision in quantity, quality, and scheduling of returns, make the course of product returns more complex [14]. Also, manufacturing firms are encouraged by globalization policies to produce environmentally friendly products which offer a sustainable competitive advantage [15]. According to Venkatesh et al. the number of recalls is on the rise every year and this is seriously affecting public health, therefore, the regulatory authorities and pharmacovigilance must screen the pharmaceutical organizations carefully to decrease the number of recalls that are currently happening [2]. It is challenging for most manufacturing pharmaceutical companies to accept the reverse logistics of medicine as the supply chain process was initially implemented to produce medicine that move from suppliers to customers and not back from the customer to the supplier. According to Mbovu and Mburu (2018), manufacturing companies make the mistake of considering the reverse logistics process as an afterthought and further assume that by producing the right product automatically all the right components are in place and consumers will be happy [16].

In 2015 Johnson \& Johnson recalled Benylin original and Benylin with codeine - due to it being delivered in the wrong country because of a set-up error. The enclosed package leaflets of Johnson \& Johnson Benylin original and Benylin with codeine were in Portuguese and not in English as these products were intended to be delivered in Mozambique. Since the information on the leaflet was not in English, it did not meet the South African customers' requirements-as they did not understand the information within the leaflet [17]. Drugs are normally returned by the consumer to the retailer, then go to the wholesalers and distributors, and are finally returned to the manufacturers (which is the focus of this research study). Recalling a drug is very expensive because of financial losses, the image of the company, and because of the risk of lawsuits from consumers [2]. Government, society, customers, investors, employees, regulators, and suppliers are some of the many stakeholders in reverse logistics firms and they have an important influence on the enterprises' performance, and on the external environment [14].

The concept of reverse logistics has received considerable attention in the last decades [12]. Reverse logistics practices are being more and more employed by the pharmaceutical industry in their supply chain activities to be more sustainable [18]. Shaik (2015) states that it is very important for companies to develop an effective reverse logistics 
enterprise performance measurement system, as this is significant in understanding the concept of the comprehensive performance-measurement background for reverse logistics enterprises and for addressing specific reverse logistics performance characteristics and magnitudes [14]. The transport process is one of the important activities in reverse logistics; and it is defined as the actual movement of mechanisms, goods, and resources from one point to another point within the reverse logistics network. Pienaar et al. (2012) suggest that by monitoring the different stages in reverse logistics, the performance of manufacturing companies can be measured, which would include [6]:

\section{Receipt}

- There can be a variety of transport operators for the delivery of returned goods from retail outlets back to the warehouse;

- Goods returned are received at dedicated or combination-receiving doors in the warehouse;

- Separately from normal-inbound products; and

- Receiving doors devoted to product returns are generally located near the returns-processing area.

\section{Returns Processing}

- More sorting and capturing of data; and

- Audit of the returns is normally implemented by many companies.

\section{Returns Analysis}

- Decide on the pathway that each item should take (dispose of); and

- The returns analysis stage is only complete after the business has entered all the recordable data on the product, customer, vendor, etc., which is obtainable before product disposition.

\section{Support Operations}

- Returned items are distributed, according to where they must go; and in this case, they should be destroyed - since drugs and medicines cannot be repaired or refurbished.

Challenges and problems in the manufacturing pharmaceutical companies lead to returns, and this might be because of surplus stock and the production of non-moving drugs (owing to several disposable drugs in the system).

\section{1-2- Challenges of Managing Reverse Logistics in the Manufacturing Pharmaceutical Industry}

There are numerous challenges in reverse logistics ranging from gatekeeping, management implications, waste elimination, miscommunication, product recalls, transportation, and damages within the pharmaceutical industry, as well as supporting managers in recovering their organizational performance and therefore reducing their financial losses. Rajagopal et al. (2015) suggest that "there are several concerns about environmental issues and sustainable logistics". Medication cannot be disposed of anywhere because of environmental regulations and must be disposed of lawfully [12]. According to Narayana et al. (2019) there are government protocols that naturally command product recovery from markets for safe disposal relating to the shelf life, the threat of counterfeiting, adulteration of the medicines and this leaves no scope for other value recovery options like chemical remanufacturing, refurbishing or recycling [18]. More profuse return policies amplified environmental regulations, the cumulative enforcement of take-back laws, an increase in financial returns, growing consumer demands, and a decent corporate image which have forced companies to face the challenges of strategically managing the returns and rejected products [14]. The design of a reverse logistics technique is a major challenge, since if it is not designed correctly; the system will be ineffective and will lead to loss of profit [19].

Reverse logistics is given little priority hence many organizations do not have defined procedures or the determination to address it [12]. Transactions occur in a highly competitive environment and accommodating product returns can cause severe challenges for the management of logistics. According to Rajagopal et al. (2015), strategic planning and forecasting appear to be one of the numerous trials encountered in reverse logistics [12]. The development of performance measurement for reverse logistics - for its efficiency and effectiveness - remains one of the most significant challenges for reverse logistics companies [14]. There are three reverse logistics challenges that manufacturing pharmaceuticals face: the formal reverse logistics evolution, the regulatory/stakeholders' education, and the environmental risk [20]. Moreover, Samarasinhe et al. (2019) explain that insufficient reverse logistics information and expertise is another noteworthy challenge to have successful reverse logistics implementation, which can be solved through educating and training employees [21].

Some of the challenges that occur are retailer to manufacturer conflict, deteriorating market value due to time delays, quantity and timing, lack of formal operating events, alterations in quality, lack of performance measurement, and a 
shortage of skilled resources [14]. The management of delicate medicine could also be a challenge as there is a high likelihood that they could be damaged in transit, resulting in huge losses. Firms can try to avoid this by cultivating sound packaging standards and educating transporters on how to handle such goods. Lack of forecasting can lead to surplus inventory which could also be a challenge, as it might lead to outdated products within manufacturing pharmacies.

Shaik(2015) states that reverse logistics effectiveness allows manufacturers a chance to improve their competitiveness by building consumer confidence through the handling of returned products, liberalized returns policies, operations of take-back networks, and green aspects of performance [14]. After what has been said in literature by Trochu et al. [4]; and John et al. [5], it should be recognized that reverse logistics as an area of study is expanding and is becoming more important. Since there the pharmaceutical industry faces challenges and huge competition, there is a need to adopt strategies and to develop actions that can better assist in the reverse flow of drugs [20]. The management and understanding of reverse logistics are significantly improving as many manufacturing pharmaceutical companies that did not initially put in much time and energy into it, are beginning to see its importance. Therefore, properly implemented and managed reverse logistics in pharmaceutical supply chains became more demanding in the wake of challenges [13].

Returns in the manufacturing pharmaceutical industry are on the rise and it is becoming a growing concern for the companies affected. Badenhorst (2017) further indicated that management is also implicated in these challenges by the following organizational barriers [22]: (i) lack of commitment by managers; (ii) lack of internal coordination; (iii) lack of awareness and management initiation; (iv) lack of strategic planning; (v) resistance to change; and (vi) lack of knowledgeable personnel resources and training. This has led to the identification of reverse logistics challenges, such as: lack of skills, technology, and transport, etc. in manufacturing pharmaceutical companies in the City of Tshwane. This study aims to examine reverse logistics challenges (as mentioned in the research problem above) in manufacturing pharmaceutical companies in the City of Tshwane in South Africa.

\section{2- Research Design and Methodology}

In the previous sections, reverse logistics, reverse logistics in the manufacturing pharmaceutical industry, challenges of managing reverse logistics in the manufacturing pharmaceutical industry, the research problem, and the research objectives were discussed. Based on this, this section will depict the research process, research philosophy, research design, and the research approach followed in this study. Furthermore, the sampling design, data collection procedure, data quality control, and data analysis will be presented. These will explain the research objectives. Figure 1 depicts the steps followed in the research design and approach.

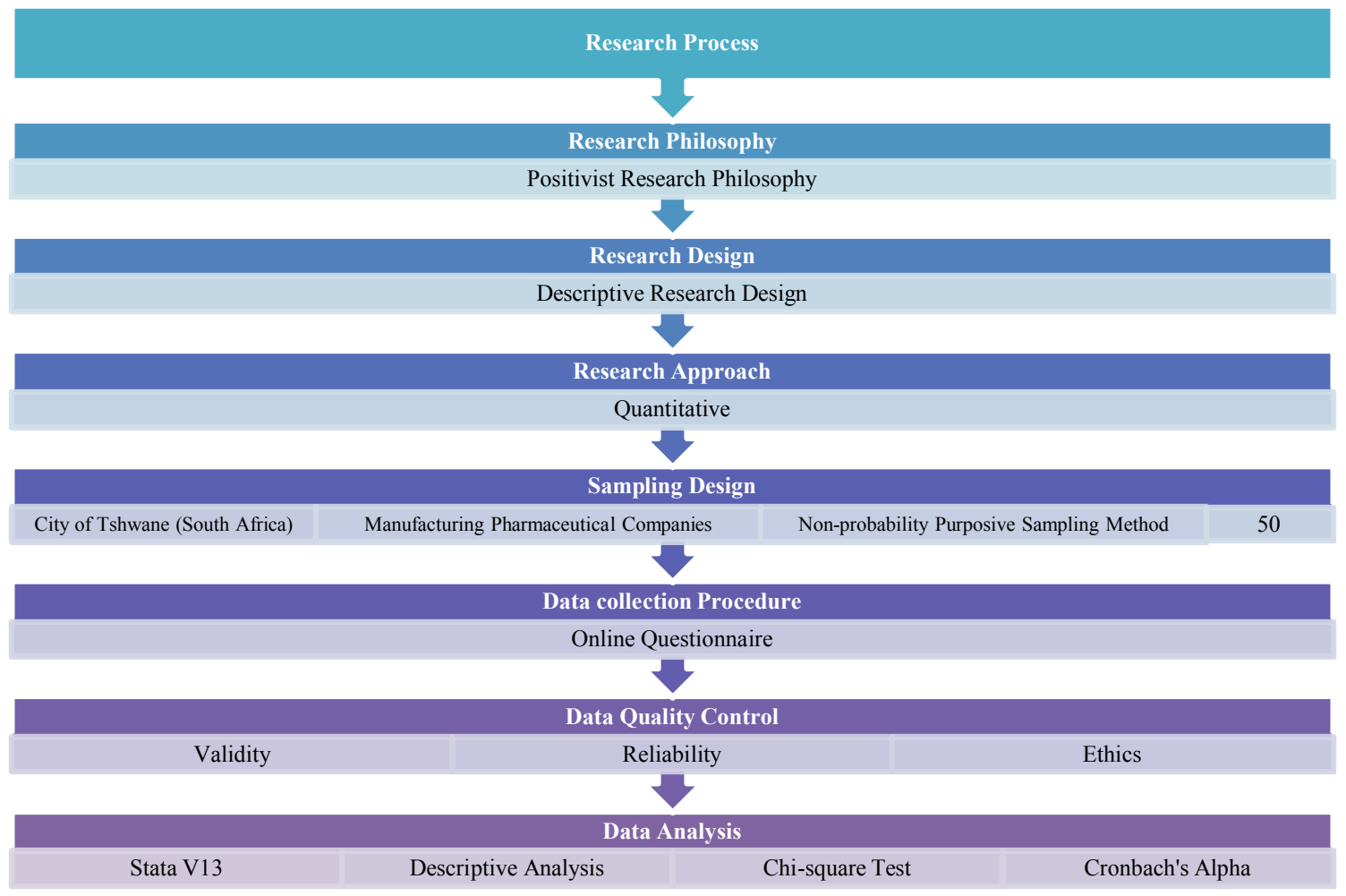

Figure 1. Research design and approach. 
This study as depicted in Figure 1 followed the empirical research design, where a positivist research philosophy was employed. Furthermore, the research design was descriptive, where a survey was conducted, and statistics were used. The study adopted quantitative research (which is measuring variables that are quantified) because this research used numerical data in a systematic and objective way that had to be analyzed. "Quantitative research is defined as the process that is systematic and objective in its ways of using numerical data from only a selected subgroup of a universe (or population) to generalize the findings to the universe that is being studied" [23]. This quantitative study was appropriate since the study was well designed using SurveyMonkey, which was properly constructed with a worded questionnaire and sent to the relevant respondents through e-mail. The sampling design, collection procedure, data quality control, and data analysis will further be discussed in the sections to follow.

\section{2-1- Population and Sampling}

This study used non-probability purposive sampling since it is mostly focused on the opinions and the perspectives of the employees involved. There are 199 manufacturing pharmacies around Gauteng [24]. The present study targeted the 100 (unit of analysis) manufacturing pharmaceutical companies based in the City of Tshwane. The sample size was set at 50 manufacturing pharmaceuticals which were selected randomly from the 100. Questionnaires were distributed via SurveyMonkey to one-three (1-3) manufacturing or production personnel, one-three (1-3) logistics or operations managers, one-three (1-3) factory managers, one-three (1-3) procurement managers or personnel and, one-three (1-3) sales personnel (SurveyMonkey can be sent to an enormous amount of people comprising individuals, who are located from afar, less time consuming and less expensive). Managers and decision-makers would receive assistance from the performance-measurement structure (e.g. human resources), which is also linked to strategic management; and it would help assess the status of the firms' performance [14]. This was done to obtain their perspectives and opinions about the topic at hand.

\section{2-2- Data Collection}

A quantitative method was used to effectively examine reverse logistics challenges in manufacturing pharmaceutical companies as there is currently limited research in South Africa on the subject. The study aimed to make observations and describe the characteristics of the workers within the firms. This was done so that the results could provide adequate insight into whether the research objectives, namely, investigating the challenges of reverse logistics, have been attained. Data were collected using a survey administered to the selected workers within the firms. SurveyMonkey was used to send questionnaires to the relevant respondents who deal with medicine, reverse logistics challenges, customer complaints, and queries in each of the fifty (50) manufacturing companies. SurveyMonkey is administered online, which is less time-consuming and less expensive and it can be sent to individuals who are situated far away. It also allowed the researcher to use different types of questions. The questionnaire took no longer than 20 minutes of the respondent's time to complete.

\section{2-3- Validity and Reliability}

According to Bryman et al. (2017) "validity addresses the question of whether or not a measure really reflects the concept that it is supposed to capture" [25]. Reliability is a very important aspect that researchers should consider when conducting a pilot or/and the main study. To ensure validity and reliability, the researcher adapted previous researchers' questions in this field and took it upon herself to send out personal e-mails to the required personnel that work in the manufacturing pharmaceutical companies that deal with reverse logistics challenges (manufacturing or production personnel, logistics or operations managers, factory managers, and sales personnel), with an attached link to the questionnaire. This was to make sure that the researcher measures what is needed. Cronbach's alpha was used to test the reliability of the instrument. The researcher conducted this research in a validly and reliably.

\section{2-4- Data Analysis}

Data analysis was conducted by using the Stata V13 statistical software. Stata V13 is similar to Statistical Package for the Social Sciences (SPSS), which is possibly the most utilized computer software when analyzing quantitative data [25]. Descriptive analyses were used, which is the usual analysis approach to discover and obtain a "feel" for the data. The eventual findings were discussed at length (including tables and graphical illustrations), and they were used as recommendations to improve reverse logistics practices and performance in the manufacturing pharmaceutical companies. To ensure the reliability of the findings, Cronbach's alpha coefficient was further used.

\section{3- Results}

In this section, some of the results found in this research are presented and discussed. In conducting this research, the researcher required answers from individuals that deal with reverse logistics in the manufacturing pharmaceutical companies. The respondents had to first determine which role they played in their respective manufacturing pharmaceutical company. 


\section{3-1- Position in Organization}

There are different positions in the manufacturing pharmaceutical companies, such as logistics manager, operations manager, factory manager, procurement manager, personnel manager, manufacturing or production personnel, and sales personnel. Table 1 shows that there was a good response of $91.33 \%$ from the priority personnel that comprised of the target for this questionnaire (manufacturing or production personnel, logistics or operations managers, factory managers, procurement managers or personnel and sales personnel) [26].

Table 1. Position in organization.

\begin{tabular}{cccc}
\hline Position & Frequency & Percentage (\%) & Cumulative (\%) \\
\hline Logistics manager & 12 & $9.45 \%$ & $9.45 \%$ \\
Operating manager & 11 & $8.66 \%$ & $18.11 \%$ \\
Factory manager & 13 & $10.24 \%$ & $28.35 \%$ \\
Procurement manager & 22 & $17.32 \%$ & $45.67 \%$ \\
Personnel manager & 19 & $14.96 \%$ & $60.63 \%$ \\
Manufacturing or production personnel & 29 & $22.83 \%$ & $83.46 \%$ \\
Sales personnel & 10 & $7.87 \%$ & $91.33 \%$ \\
Other & 11 & $8.66 \%$ & $99.99 \%$ \\
Total & 127 & $99.99 \%$ & \\
\hline
\end{tabular}

${ }^{*}$ Does not total to $100 \%$ due to rounding off to two (2) decimal places.

Many of the respondents employed at the manufacturing pharmaceutical company were manufacturing or production personnel (22.83\%). The data further showed that a small number of $8.66 \%$ (other) of the employees that responded to the questionnaire were: quality personnel, production associates, specialty technicians, production supervisors, quality assurers, regulators, and interns. The results indicate that there were a few personnel managers (14.96\%).

\section{3-2- Development Programs}

A percentage of $22 \%$ of the manufacturing pharmaceutical companies that are based in the City of Tshwane does not have development programs for staff members and this indicated that the firms need to implement development programs for their staff to be better equipped to deal with the challenges of reverse logistics of the medication. Further results are depicted in Figure 2 [26].

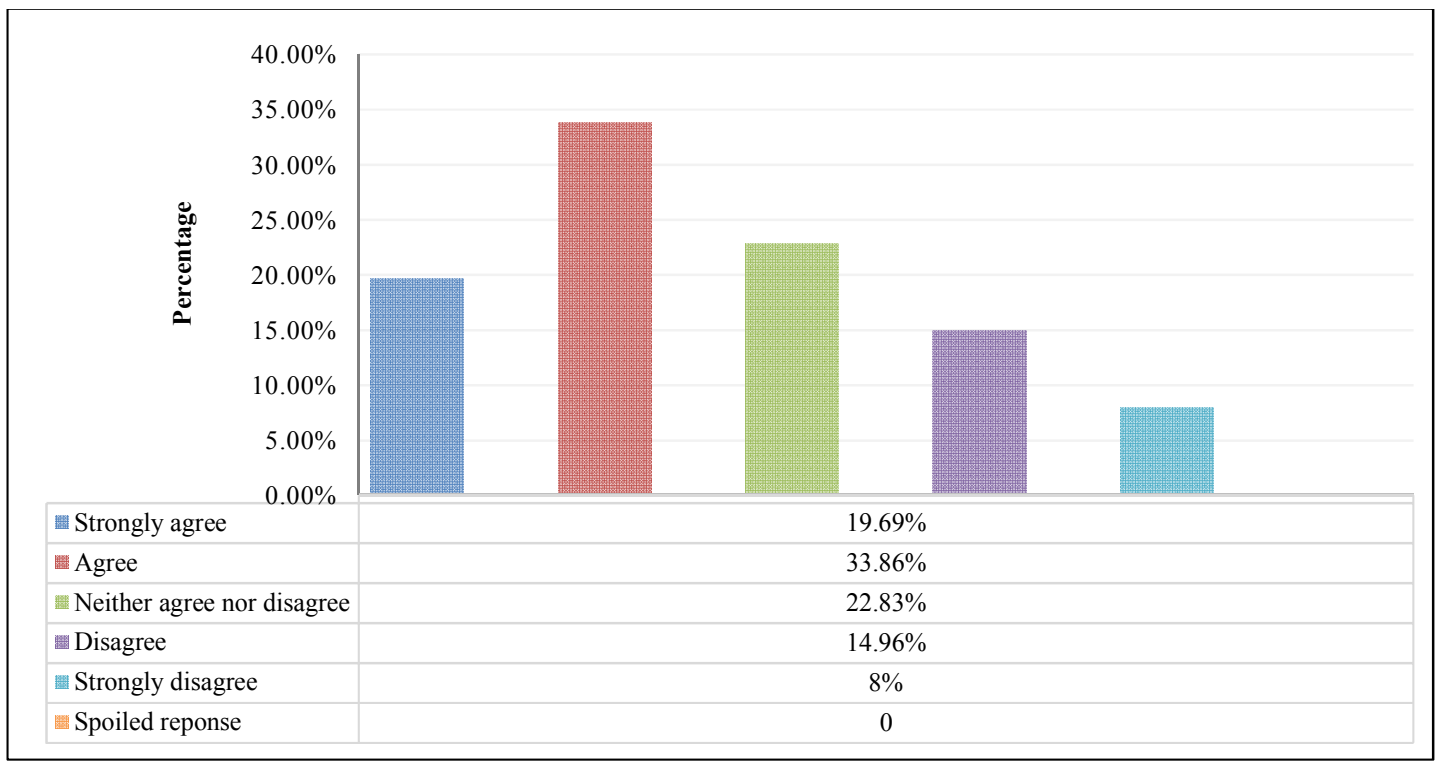

Figure 2. Histogram of the respondents' perceptions on development programs for staff.

A Chi-square test was also performed to examine the relationship between the positions held in the organization and development programs. The results indicated that there is no significant relationship between the positions held in the organization and the perceptions regarding development programs $\mathrm{X} 2(2)=1.1876, \mathrm{p}=0.552$. 


\section{3-3-Technological Capabilities}

The results also revealed that one of the strategies used by manufacturing pharmaceutical companies in the City of Tshwane is technology, but the technology being used should be advanced and current since the one that is currently being used is outdated. Technological resource capability can diffuse merchandise information effectively for manufacturing pharmaceutical companies through to the appropriate practical parts of the reverse logistics system [14]. This makes technology a very important component of the processes used, and the transactions conducted. The respondents indicated that having advanced technology is very important in assisting with the challenges faced in their firm. The results showed that $52.38 \%$ of the respondents believed that it has a very high influence, a further $42.06 \%$ indicated that it does have an influence, $3.97 \%$ of the respondents indicated that it has a medium influence and only $1.59 \%$ of the respondents felt that it had a low influence. The Cronbach's alpha $=0.9224$ indicating that there is internal consistency since the alpha value is above 0.70 ; therefore, it is considered acceptable in most social science research situations, which suggests that there is internal consistency among the items. This is further supported by Quinlan, Babin, Carr, Griffin and Zikmund [27] who mention that a coefficient $\alpha$ below 60 has poor reliability, a coefficient $\alpha$ between 60 and 70 has fair reliability, a coefficient $\alpha$ between 70 and 80 has good reliability, and lastly, a coefficient $\alpha$ above 80 has very good reliability.

\section{3-4- Transportation}

The use of transportation is very important for any type of firm, as goods are moved to and from with transport. Transport is essential for waste management because of its importance in reverse logistics and also because of the growing demand for green products and the impact that reverse logistics has created on the environment [28]. Agrawal and Choudhary [29] suggest that the major reverse logistics cost is transporting - as much as $25 \%$ or more of the total reverse logistics costs are the transportation costs. All respondents indicated that transport does play an important role as indicated in Figure 3 [26].

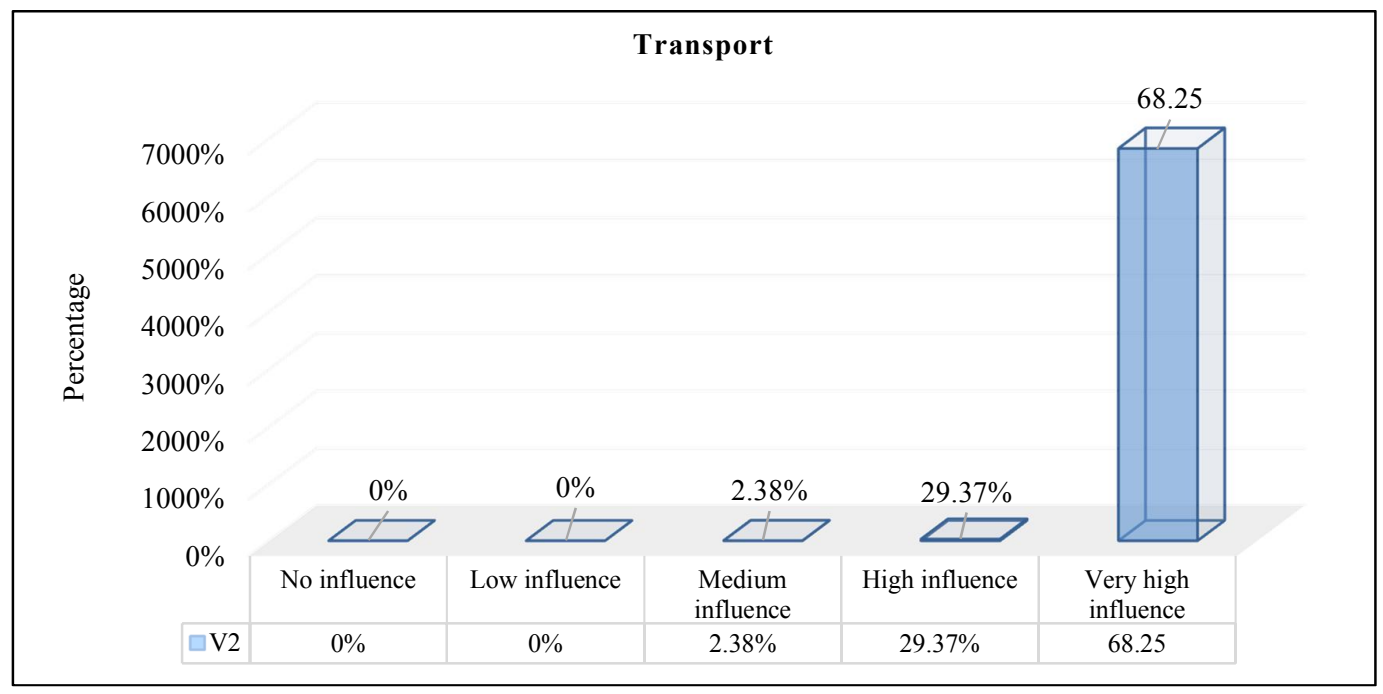

Figure 3. Histogram of respondents' perceptions regarding transport in their manufacturing pharmaceutical companies.

The actual physical movement of goods from one point to the next inside the reverse logistics system is considered as transportation in the reverse logistics procedure [29]. The respondents in the manufacturing pharmaceutical companies indicated that transport has a very high influence and that it does play a very important role.

\section{3-5-Gatekeeping}

As mentioned in the literature review, the return of drugs is usually due to damages in transit. Gatekeeping is therefore one of the processes that need to take place. Table 2 indicates that $32.54 \%$ of the respondents indicated that gatekeeping has a very high influence and if not handled correctly, it causes delays in the process - none of the respondents indicated that it does not have any influence [26]. Many respondents (57.94\%) indicated that it has a high influence. 
Table 2. Gatekeeping.

\begin{tabular}{cccc}
\hline Gatekeeping & Frequency & Percentage (\%) & Cumulative (\%) \\
\hline No influence & 0 & $0 \%$ & $0 \%$ \\
Low influence & 1 & $0.79 \%$ & $0.79 \%$ \\
Medium influence & 11 & $8.73 \%$ & $9.52 \%$ \\
High influence & 73 & $57.94 \%$ & $67.46 \%$ \\
Very high influence & 41 & $32.54 \%$ & $100 \%$ \\
\hline Total & 126 & $100 \%$ & \\
\hline
\end{tabular}

The results indicate that gatekeeping is one of the essential processes of reverse logistics and it must be taken into careful consideration. There are other processes that are important when dealing with reverse logistics, such as collection and storing. The collection and receiving of these returned drugs are very important and the respondents of the manufacturing pharmaceutical companies did indicate that in their responses.

\section{3-6- Collection}

The respondents viewed the collection process as one of the challenges being faced by their companies. The responses indicated that only $3.97 \%$ of the respondents feel that the collection process is not a challenge. The results further indicated that $96.03 \%$ view it as a high or very high influence. None of the respondents felt that collection has no influence. Clearly, the collection process can be viewed as a challenge for many manufacturing pharmaceutical companies.

\section{3-7- Challenges}

Figure 4 indicates the overall results of respondents' beliefs as to whether challenges are being faced by the manufacturing pharmaceutical companies [26].

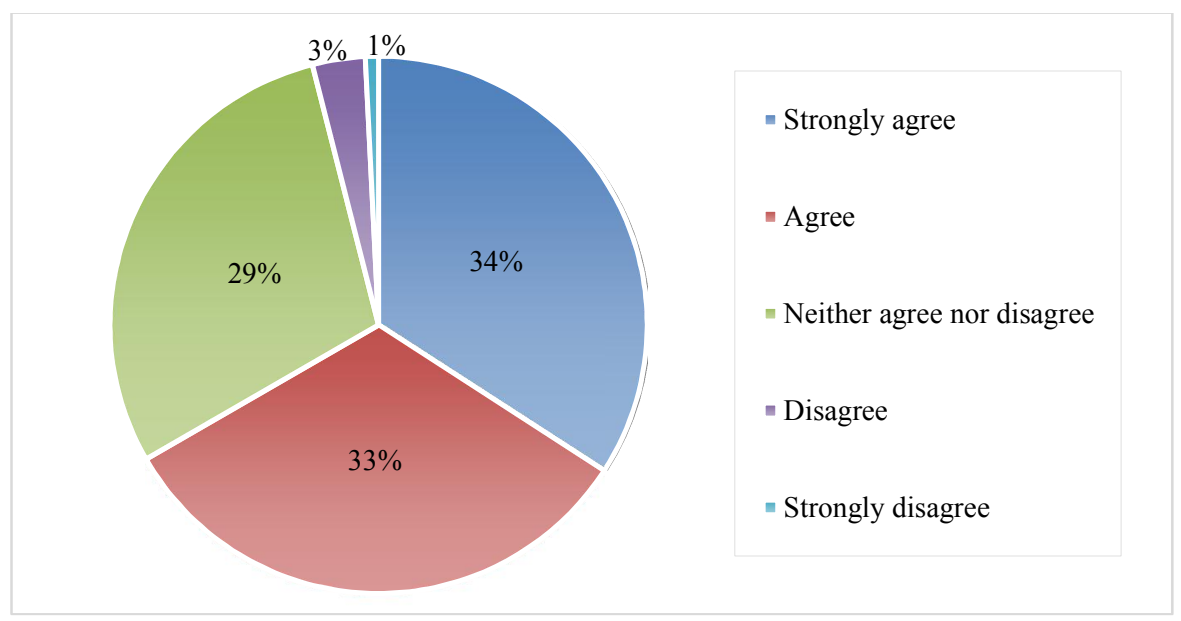

Figure 4. Pie chart of respondents' perceptions regarding challenges in their manufacturing pharmaceutical companies.

Figure 4 further indicates that only $3.96 \%$ of the respondents disagree that there are challenges in their manufacturing pharmaceutical companies. According to Waqas et al. [15], regardless of the existence of challenges, numerous firms' have shown an interest in effectively and efficiently adopting reverse logistics. A Cronbach alpha test was conducted (Table 3 ) to test the reliability and the Cronbach's alpha was $=0.9264$, which indicated that there is internal consistency since the alpha value was above 0.70 , which is considered acceptable in most social science research situations [26].

Table 3. Cronbach's alpha test.

\begin{tabular}{ccccccc}
\hline Item & Obs & Sign & $\begin{array}{c}\text { Item-test } \\
\text { correlation }\end{array}$ & Item-rest correlation & $\begin{array}{c}\text { Average inter-item } \\
\text { Covariance }\end{array}$ & Cronbach's alpha \\
\hline 127 & + & 0.8433 & 0.7979 & 0.4483915 & 0.9264 \\
\hline
\end{tabular}




\section{4- Discussion}

Manufacturing pharmaceutical companies must make sure that they meet their customers' expectations and ensure that they satisfy their needs. Logistics plays a major role in making sure that the customers' needs are satisfied; since goods must be moved from the supplier to the end-user, and the right goods must be delivered at the right time, to the right place. When reverse logistics occurs, it is mainly because of unforeseen circumstances. Customers of the manufacturing pharmaceutical companies return medication mainly because of defects, damages, and expired medicine. Since reverse logistics in the context of medicine might cause environmental complications, manufacturers need to take into consideration the environmental laws when such products are being returned and being disposed of. Many challenges are being faced by manufacturing pharmaceutical companies as indicated by the respondents. The study suggests that all manufacturing pharmaceutical companies learn more about reverse logistics, its processes, its strategies, and its advantages and disadvantages. Learning more about the development processes can give the manufacturing pharmaceutical companies a leading edge and a competitive advantage in the industry. Maintaining good relationships throughout the market with other manufacturing pharmaceutical companies and inside the business (since there are stages and a chain that must be followed in a company) is important for the success of the companies.

Customer focus is very important since the production of drugs is done to satisfy customer requirements; it is recommended that customers are put first and are treated with respect, and that all their queries are handled in time and with respect. Without customers, there will not be a need to manufacture all the drugs; thus, customers are essential to the manufacturing pharmaceutical companies. Gatekeeping, transportation, collection, storing, information-sharing, and sorting should all be done in a time-effective manner; since all these processes consume time, money, and resources. These challenges that are being faced might not be limited to the City of Tshwane but may also be encountered in other cities, provinces, and countries. The study suggests that further research would enhance this study. Further research can be done on any other organization or reverse logistics challenges in the manufacturing pharmaceutical companies in any other city, province, or country. Reverse logistics models can be created and adopted in future research to deal with reverse logistics. Returns can also be looked at from the consumers' point of view as well as the retailers' point of view. Continuous improvements about reverse logistics processes, procedures, and finances should be the aim of all firms.

\section{5- Conclusion}

The usual way of moving goods in the manufacturing pharmaceutical companies is from the suppliers to the customers. In the reverse logistics process, the goods are moved from the customer to the supplier. This could be due to drug defects/damages/expiration. A lot of manufacturing pharmaceutical companies in the City of Tshwane did not predict that drugs will be returned since goods are only produced to move forward. Reverse logistics has been in existence as far back as logistics; though many firms do not want to undergo reverse logistics because they view this as being a financial loss. The researcher realized that the reverse logistics of drugs is not as easy as it sounds as drugs cannot be resold or refurbished. When drugs are returned due to defects/damages, the only option is to destroy them. Drugs cannot just be disposed of anywhere as they are harmful to the environment; and certain environmental regulations, and laws need to be followed. There is an absence of reverse logistics studies with regard to manufacturing pharmaceutical companies and that is another reason why this study was undertaken. The expectation for this study is to make management aware of the challenges that are being faced in the reverse logistics of medicine. Management must realize the importance of having reverse logistics development programs (training) for staff to enable them to deal with reverse logistics challenges. The many manufacturing pharmaceutical companies must understand the significance of applying models for reverse logistics since it is an imperative part of logistics.

\section{6- Declarations}

\section{6-1-Author Contributions}

Conceptualization, M.S.M.M. and K.R.L.; methodology, M.S.M.M. and K.R.L.; writing-original draft preparation, M.S.M.M. and K.R.L.; writing - review and editing, M.S.M.M. and K.R.L. All authors have read and agreed to the published version of the manuscript.

\section{6-2-Data Availability Statement}

The data presented in this study are available on request from the corresponding author.

\section{6-3-Funding}

This article is based on the researchers Magister Technologiae (M-Tech, Tshwane University of Technology) in logistics and was funded by the National Research Foundation (NRF), which the researcher was nominated for. 


\section{6-4-Conflicts of Interest}

The authors declare that there is no conflict of interests regarding the publication of this manuscript. In addition, the ethical issues, including plagiarism, informed consent, misconduct, data fabrication and/or falsification, double publication and/or submission, and redundancies have been completely observed by the authors.

\section{7- References}

[1] Abbas, Haidar, and J. Farooquie. "Framework for reverse logistics practices in pharmaceutical supply chains." International Journal of Pure and Applied Mathematics 119, no. 16 (2018): 2343-2358.

[2] Venkatesh, M.P., Bigoniya, D. andPramod Kumar, T.M. "Pharmaceutical product recall procedures in India, South Africa and China." International Journal of Pharmaceutical Sciences Review and Research 18 (2017): 98-104.

[3] Ayvaz, Berk, Bersam Bolat, and Nezir Aydın. "Stochastic Reverse Logistics Network Design for Waste of Electrical and Electronic Equipment." Resources, Conservation and Recycling 104 (November 2015): 391-404. doi:10.1016/j.resconrec.2015.07.006.

[4] Trochu, Julien, Amin Chaabane, and Mustapha Ouhimmou. "Reverse Logistics Network Redesign under Uncertainty for Wood Waste in the CRD Industry." Resources, Conservation and Recycling 128 (January 2018): 32-47. doi:10.1016/j.resconrec.2017.09.011.

[5] John, Sajan T, R Sridharan, P N Ram Kumar, and M. Krishnamoorthy. "Multi-Period Reverse Logistics Network Design for Used Refrigerators.” Applied Mathematical Modelling 54 (February 2018): 311-331. doi:10.1016/j.apm.2017.09.053.

[6] Pienaar, Wessel J., Wessel J. Pienaar, and John J. Vogt. Business logistics management: A value chain perspective. Oxford University Press, 2012.

[7] De Villiers, Gerard, Gideon Nieman, and Wesley Niemann, eds. Strategic logistics management: A supply chain management approach. Van Schaik Publishers, 2017.

[8] Wheels24. Ford Kuga recalls in SA, Phase 2' begins, more fixes for SUVs. (2017). Available online: http://m.wheels24.co.za/wheels24/News/ford-kuga-recall-in-sa-phase-2-kicks-off-more-fixes-for-suvs-20170726 (accessed on 29 May 2020).

[9] WHO, World Health Organization. Weekly bulletin on outbreaks and other emergencies. (2018). Available on: http://apps.who.int/iris/handle/10665/272281 (accessed on 28 May 2020).

[10] Department of Health. Listeriosis outbreak situation report. (2018). Available online: https://www.nicd.ac.za/wpcontent/uploads/2018/07/Listeriosis-outbreak-situation-report-_26July2018_fordistribution.pdf (accessed on 28 May 2020).

[11] Sorkun, Metehan Feridun, and Meltem Onay. "The Effects of Companies' Reverse Logistics Motivations on Their Reverse Logistics Networks." Strategic Design and Innovative Thinking in Business Operations (2018): 3-21. doi:10.1007/978-3-31977622-4_1.

[12] Rajagopal, Premkumar, Veera Pandiyan Kaliani Sundram, and Babudass Maniam Naidu. "Future directions of reverse logistics in gaining competitive advantages: A review of literature." International journal of supply chain management 4, no. 1 (2015): $39-48$.

[13] Abbas, Haidar. "Barriers to Reverse Logistics Practices in Pharmaceutical Supply Chains: An ISM Approach." International Journal of Business Excellence 16, no. 1 (2018): 47. doi:10.1504/ijbex.2018.10015756.

[14] Shaik, M. “Comprehensive performance measurement methodology for reverse logistics enterprise." Ph.D. dissertation, University of Windsor, Canada, (2015).

[15] Waqas, Muhammad, Qian-li Dong, Naveed Ahmad, Yuming Zhu, and Muhammad Nadeem. "Critical Barriers to Implementation of Reverse Logistics in the Manufacturing Industry: A Case Study of a Developing Country." Sustainability 10, no. 11 (November 14, 2018): 4202. doi:10.3390/su10114202.

[16] Mbovu, D.k. and Mburu, D.K. "Influence of reverse logistics practices on enhancing competitiveness in manufacturing firms in Kenya', a case of east African breweries LTD.”International Journal of Supply Chain Management 3, no. 1 (2018): 1-16.

[17] Johnson \& Johnson. Johnson \& Johnson recall letter. 2021. Available online: https://www.jnj.com/johnson-johnson-consumerinc-issues-voluntary-recall-of-specific-neutrogena-and-aveeno-aerosol-sunscreen-products-due-to-the-presence-of-benzene https://www.sahpra.org.za/wp-content/uploads/2019/10/MSA-cough-and-cold-medicines-1.pdf (accessed on 29 June 2021).

[18] Narayana, Sushmita A., Rupesh K. Pati, and Sidhartha S. Padhi. "Market Dynamics and Reverse Logistics for Sustainability in the Indian Pharmaceuticals Industry." Journal of Cleaner Production 208 (January 2019): 968-987. doi:10.1016/j.jclepro.2018.10.171. 
[19] Rubio, Sergio, and Beatriz Jiménez-Parra. "Reverse Logistics: Overview and Challenges for Supply Chain Management." International Journal of Engineering Business Management 6 (January 1, 2014): 12. doi:10.5772/58826.

[20] Campos, Elaine Aparecida Regiani de, Istefani Carisio de Paula, Regina Negri Pagani, and Patricia Guarnieri. "Reverse Logistics for the End-of-Life and End-of-Use Products in the Pharmaceutical Industry: a Systematic Literature Review." Supply Chain Management: An International Journal 22, no. 4 (June 12, 2017): 375-392. doi:10.1108/scm-01-2017-0040.

[21] Samarasinhe, Kalani Petronila, and Wang Haijun. "Challenges in implementing reverse logistics practices in Sri Lanka." International Journal of Information, Business and Management 11, no. 3 (2019): 113-124.

[22] Badenhorst, A. "Management practices to mitigate barriers in reverse logistics." Journal of Contemporary Management 14 (2017): 595-623.

[23] Maree, K.. First steps in research. Second edition. Van Schaik, 2018. Available online: https://www.vanschaiknet.com/ book/view/347 (accessed on 29 May 2020).

[24] The South African Pharmacy Council, Statistics for registered persons and organisations, Organisations by sector. Available online: https://interns.pharma.mm3.co.za/Statistics/PharmaciesBySector?class=btn\%20btn-primary (accessed on 28 May 2020).

[25] Bryman, A., Bell E., Hirschsohn, P., Dos Santos, A., Du Toit, J., Masenge, A., Van Aardt, I. and Wagner, C. Research methodology. Business and Management contexts. Eighth edition. . Oxford University Press Southern Africa, (2017).

[26] Makaleng, Mpho Sharon Makgedi. "Reverse Logistics Challenges In Manufacturing Pharmaceutical Companies in the City of Tshwane." MSc diss., Tshwane University of Technology, (2017).

[27] Quinlan, C., Babin, B., Carr, J., Griffin, M. and Zikmund, W.G. Business research methods. Second edition. Cengage, (2019). Available online:https://www.cengage.co.uk/books/9781473760356/ (accessed on 29 May 2020).

[28] Linford, P. and Mkansi, M. Reverse logistics. In Editors: de Villiers, G., Nieman, G. \& Niemann, W. eds. Strategic logistics management: a supply chain management approach. Second edition, Van Schaik (2017) 147-158.

[29] Agrawal, A. and Choudhary, V. 'Reverse logistics: Performance measures and their effect in product life cycle.' International Journal of Core Engineering \& Management 1, no. 2 (2014): 14-22. 